\title{
PISANA RIJEČ I BIBLIOTEKE U BOSNI I HERCEGOVINI DO XX STOLJEĆA
}

\author{
Dr. Ismet Ovčina \\ Nacionalna i univerzitetska biblioteka Bosne i Hercegovine, Sarajevo, Bosna i Hercegovina \\ National and University Library of Bosnia and Herzegovina, Sarajevo, Bosnia and Herzegovina \\ ismet@nub.ba
}

\begin{abstract}
Sažetak
Kulturno naslijeđe Bosne i Hercegovine u svim svojim vidovima i u bilo kojem vremenskom intervalu svjedoči o složenosti života na ovom tlu. U radu su predstavljeni tokovi pisane riječi i stvaranja biblioteka u Bosni i Hercegovini.

Vidjet ćemo da se upravo u domenu pisma i knjige, bolje nego u bilo kojem drugom mediju, raspoznaje prisustvo pojedinih utjecajnih sfera, kao i originalni stvaralački duh ljudi ove zemlje. U našoj zemlji u srednjem vijeku su se koristila četiri sistema pisma. To su bili grčko i latinsko pismo te glagoljica i ćirilica. Razlog tome je susret različitih civilizacija koje su se ovdje i razvijale, a ovakav primjer korištenja različitih pisama u maloj regiji je jedinstven u svijetu.

Preko pisma i knjiga dolazimo do nastanka i prvih biblioteka u Bosni i Hercegovini. Kao što su knjige jedan od bitnih elemenata za širenje pismenosti, tako su i biblioteke jedno od najvažnijih sredstava da se omogući to širenje i da knjiga dođe do čitaoca. Biblioteke i bibliotekarstvo u Bosni i Hercegovini prolazili su kroz razne faze, ali su ostajali vjerni svojoj funkciji kroz stoljeća - razvoju kulture i masovnog obrazovanja i nauke. Biblioteke su bile i ostale stub civilizacije.
\end{abstract}

Ključne riječi: pismenost, pisana riječ, biblioteke, kultura, obrazovanje, Bosna i Hercegovina

\section{Uvod}

Kulturna baština Bosne i Hercegovine veoma je bogata i raznovrsna te ćemo u ovom radu samo dotaći razvitak pismenosti i pisane riječi u Bosni i Hercegovini. Teško bi bilo u jednom radu obuhvatiti i predstaviti razvojni put pisma, knjige i biblioteke do XX stoljeća u Bosni i Hercegovini. Materija je veoma bogata pa je akcenat u ovom radu na objašnjenju osnovnih historijskih činjenica.

\section{Pisana riječ u Bosni i Hercegovini}

Pisana riječ u Bosni i Hercegovini ima dugu tradiciju koju uz pomoć pisanih spomenika, rukopisa i naučnih istraživanja možemo izučavati i govoriti o razvitku pismenosti na ovom tlu. Prve pisane tragove i pisma imamo u vrijeme ilirskog nastanjivanja Bosne. O pismenosti Ilira ne možemo govoriti jer nemamo tragove. Razvojem trgovine i trampe, putovanja, istraživanja novih svjetova i migracija, znamo da su se Iliri u skoro istom vremenskom periodu upoznali sa grčkim, etrurskim, kao i latinskim pismom. Zanimljivo je da se dva pisma sa dva različita kraja svijeta susreću u Bosni. Ti pisani tragovi datiraju iz II st. pr. n. e.

Basler smatra da je prvi primjer pisanih tragova $u$ Bosni napisan na etrursko-umbrijskom jeziku. Ispisan je na zemljanoj posudi pronađenoj na lokalitetu Pod kod Bugojna. Natpis ima tridesetak znakova te sadrži posvetu rimskim bogovima Janu i Juturni. Smatra se da je ovaj natpis na zemljanoj posudi prepis s jedne metalne vaze.

Drugi primjer prvih pisanih tragova nalazimo $u$ Hercegovini. U pitanju su novčići ilirskog plemena Daorsa koji su prigrlili utjecaje helenističke kulture. Novčići su pronađeni u ostacima zidina grada Daorson u Ošanićima kod Stoca, a datirani su u period oko III st. pr. n. e. Brončani novci imali su natpis "Daorsôn" sa prikazanim modelom broda, dok je sa druge strane prikazana ljudska glava u profilu.

Latinicu u Bosnu i Hercegovinu donose Rimljani. Najstariji latinski epigrafski natpis u Bosni i Hercegovini datira iz 36/35. god. pr. n. e. Pronađen je na lokalitetu Nerezi kod Tasovčića, nedaleko od Ča- 
pljine. Natpis iz Tasovčića su braća Papii postavili u čast Oktavijanu:

Imp(eratori) Caesari divi f(ilio) / Sicilia recepta G(aius) Papius Celsu[s] / M(arcus) Papius Kanus fratres [Imperatoru, sinu božanstvenog Cezara, u čast osvojenja Sicilije, Gaj Papije Celzo i Marko Papije Kanus, braća (podigoše)]. (Basler 1982)

Braća Papii su bili dio ugledne italske porodice iz Narone sa posjedima u Čapljini i Tasovčićima, te su vjerovatno i dobar dio svoga bogatstva stekli trgovinom sa Daorsima.

Najviše natpisa iz doba Rimljana nalazimo na nadgrobnim spomenicima i oltarima bogova. To su bili i hvalospjevi, radosne vijesti, zahvala bogovima, kao i tužni događaji poput smrti.

Dokaz pismenosti u rimskom dobu na prostoru naše zemlje jest veliki broj epigrafskih spomenika od kojih je sastavljena zbirka pod imenom Corpus Inscriptionum Latinarum. Zbirka u kojoj se nalaze epigrafski spomenici $\mathrm{BiH}$ je Corpus Inscriptionum Latinarum III.

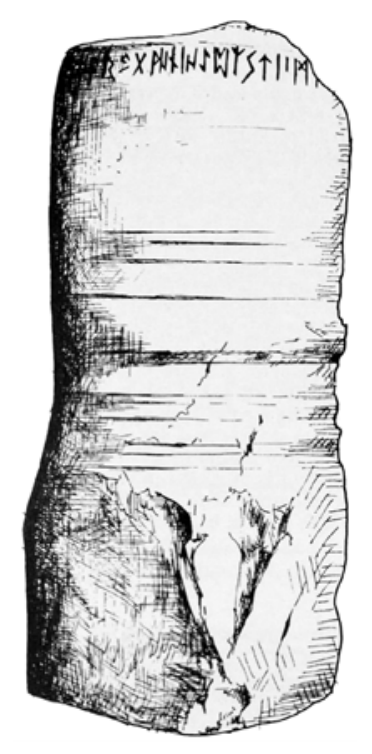

Basler govori da sa seobama u naše predjele Istočni Goti 490. godine donose svoje običaje, kulturu i pismo. Rune su u V st. zamijenile latinicu u Bosni. Primjere gotskog pisma pod imenom rune nalazimo u Brezi. Natpis je stajao na stubu pored ulaza upravne zgrade istočnogotskog kneza.

U VI i VII st. ovo područje naseljavaju Slaveni koji nisu imali svoje pismo. U knjizi Od slike do knjige Emina Memija navodi riječi prvog slavenskog filologa Črnorisca Hrabra, koji kaže da su Slaveni u početku na Balkanu pisali i računali crtama i rezama. $\mathrm{Za}$ te crte i reze se vjeruje da su bile slavenske rune urezane u drvene štapove.

U VIII st. BiH je bila u sklopu Karolinškog carstva, tako da svi pisani dokumenti dolaze sa dvora Karla Velikog. Zbog činjenice da je dvor bio daleko, kao i da su ovaj jezik rijetki razumjeli, tragova pisane riječi iz ovog perioda nema. Tek u IX st. nailazimo na prvi nama poznati tekst na latinskom jeziku ispisan predromaničkim pismom. Tekst je uklesan u gredu koja je pronađena na lokalitetu Rapovine (3 km jugozapadno od Livna).

Arhitravna greda ukrašena je karakterističnim motivima za predromaničko razdoblje, $\mathrm{u}$ donjem frizu grede isklesan je dedikacijski natpis rustičnom kapitalom na latinskom jeziku. Natpis govori o posveti crkve sv. Petru Apostolu (...FERE DIGNATVS EST AT HONORE(M) BEATI PETRI AP(OSTO)LI P(RO) REMEDIO ANIME SVE...) Iz natpisa se očituje izvorni crkveni titular Sv. Petar, kao i zavjetni dio uklesanog teksta $\mathrm{u}$ formulaciji: pro remedio anime sve, odnosno u prijevodu: za spas svoje duše. (Arheološka istraživanja u Rapovinama kod Livna 2013)

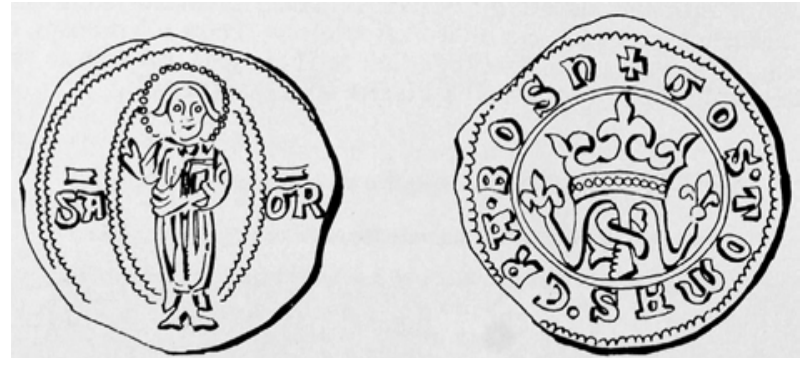

Latinicu ponovo nalazimo u BiH sa dolaskom katoličkih misionara u srednjem vijeku. Pisari u skriptorijima bosanskih vladara održavali su korespondenciju sa gradovima i državama u Evropi. Također, za vrijeme vladavine Stjepana Tomaša "u Bosni su, kao prvoj zemlji na području (...) Jugoslavije” (Čelić 1982) prvi put se na novcu pojavile na latinskom četiri riječi narodnog jezika: GOS(podin) Tomas CRA(gl) BOSN(e).

Dolaskom kršćanstva u Bosnu u X st. počinju se koristiti glagoljica i ćirilica. Glagoljica se smatra prvim pismom Slavena koje je nastalo u drugoj polovini IX stoljeća. Danas imamo mnogo različitih hipoteza o kreatoru glagoljice, ali je ipak najčešće vjerovanje da je ovo pismo razvio sv. Ćiril (Konstantin filozof). Ćiril je sa bratom sv. Metodom, na zahtjev moravskog kneza Rastislava, došao u Moravsku da običnom puku propovijeda kršćansku vjeru na slavenskom jeziku. Ova dvojica braće iz Soluna ostavila su veliki utjecaj na širem prostoru Balkana.

Braća su prevela najvažnije crkvene knjige na jezik makedonskih Slavena pisan glagoljicom. Do dolaska braće u Moravsku kršćanske crkvene i svete knjige su bile napisane na hebrejskome, grčkom i latinskom jeziku. Njihovo prevođenje smatra se stvaranjem prvog slavenskog književnog jezika i slavenske književnosti i pismenosti.

Glagoljica u Bosni nije bila toliko u upotrebi. Crkveni kodeksi su pisani glagoljicom pa su se i gla- 
goljična slova znala nalaziti u ćiriličnim rukopisima. Jedan od dokaza rane pismenosti i glagoljice na ovom prostoru je natpis na Manastirištu u Kijevcima kod Bosanske Gradiške. Natpis se nalazi na kamenu. Uklesano je muško ime u dativu -RADINU-. Marko Vego ističe da je ime napisano oblom glagoljicom i predstavlja jedan od najstarijih glagoljskih natpisa u našoj bivšoj zemlji. Smatra se da je nastao u periodu X, XI ili XII stoljeća.

Primjeri crkvenih kodeksa i knjiga na glagoljici pisani na našem tlu su Miroslavljevo evanđelje iz XII stoljeća (pisano najvjerovatnije u Humu za humskog vladara Miroslava) i Hrvojev misal (za feudalca Hrvoja Vukčić Hrvatinića). Glagoljica se u Bosni zadržala do XV stoljeća, do dolaska osmanske vlasti, a svoj procvat doživljava u Dalmaciji.

Nakon glagoljice pojavljuje se ćirilica. Ona je nastala zbog složenosti glagoljice. Novo pismo je nastalo upotrebom grčkog alfabeta. Ipak, u ćirilici su se našla slova koja ne postoje u grčkom pismu, te su ona zapravo izvorni oblici slova iz glagoljice. Jedan od najznačajnijih dokaza ćiriličnih natpisa je Humačka ploča iz X ili XI stoljeća. U kasnijim godinama se govori da je Humačka ploča iz XII stoljeća. ${ }^{1}$ Ona predstavlja ktitorski natpis na crkvi sv. Mihajla u Humcu koja se nalazi u zapadnoj Hercegovini. Pisana je ćirilicom, ali se mogu naći i neka glagoljična slova.

I u Bosni se, kao i u drugim zemljama u kojima se ćirilica razvila, razvilo pismo ćirilice. Ta ćirilica se zove bosančica. Bosančica ima i druga imena: bosanska ćirilica, bosanica, bukvica, bosansko pismo i sl. Bosančicu njen grafološki sistem izdvaja od ćirilica drugih Slavena. "Bosančicom se u srednjem vijeku, u vrijeme bosanske samostalnosti, razvila živa pismenost" (Memija 2007).

Naučnici smatraju da je primjer dokumenta napisanog ovim pismom Povelja Kulina bana. Povelja je datirana 29. 8. 1189. godine. Ona je trgovački ugovor bosanskog bana Kulina sa Dubrovnikom. Dokument je pisan dvojezično te, pored narodnog jezika, ima tekst i na latinskom jeziku. Povelja "ima višestruk značaj za povijest Bosne kao jedan od bitnih dokaza njenog postojanja kao uređene države" (Memija 2007).
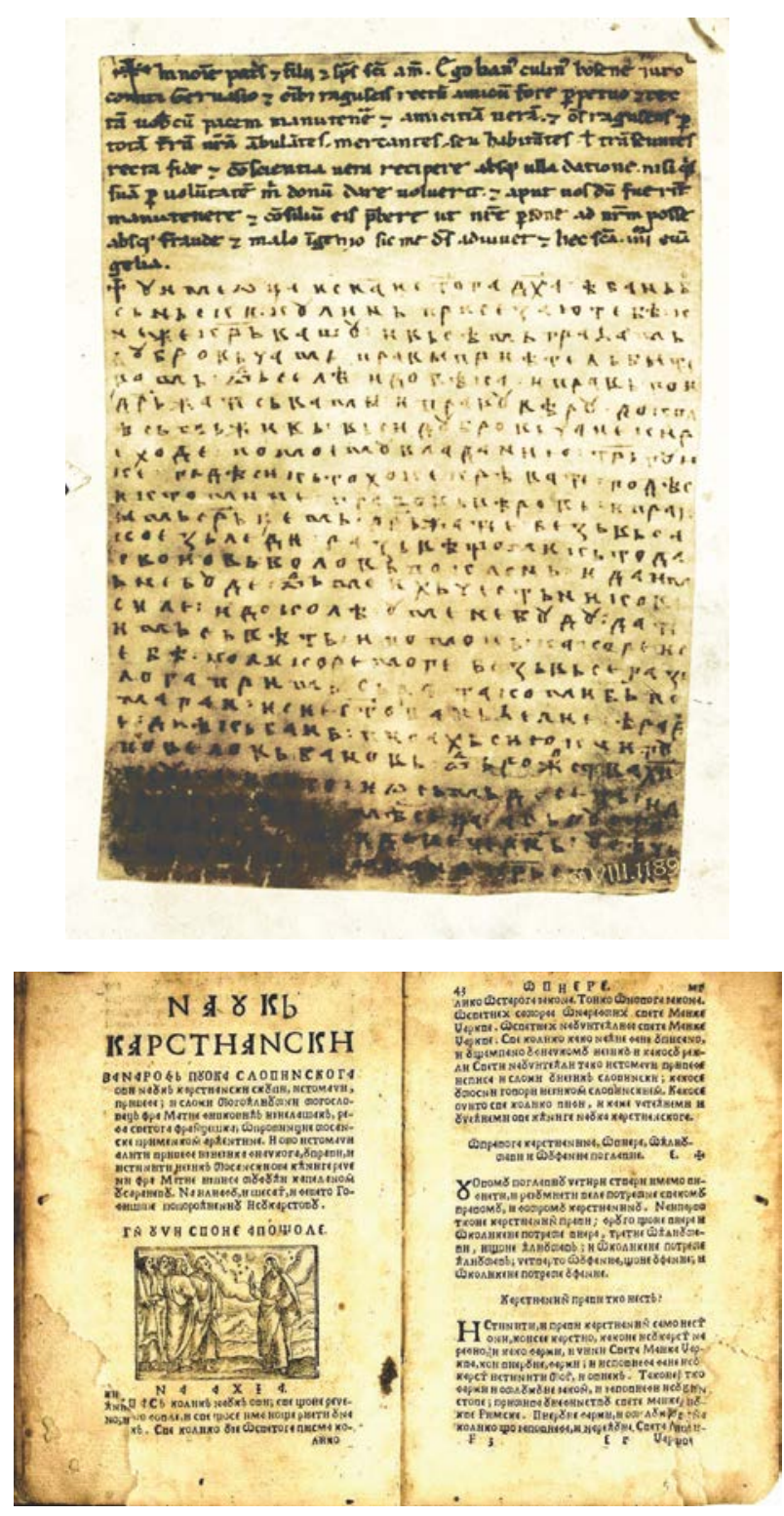

Bosančica se koristi i za vrijeme Osmanske vladavine, kao i kasnije. Franjevac Matija Divković je svoju knjigu Nauk krstjanski za narod slovinski u Veneciji 1611. godine štampao na bosančici. ${ }^{2}$ On je sam izlijevao slova koja se koriste i za ostala izdanja. Franjevci su prvi štampali knjige na bosančici u Veneciji. Bosančicu kasnije najviše upotrebljavaju Bošnjaci, sve do XIX stoljeća. Ova varijanta bosančice naziva se begovica ili žensko pismo zbog toga što su ga koristili viši slojevi i pismene žene za privatnu korespondenciju.

Pred kraj prve faze razvitka pisane riječi na bosansko-humskom tlu u pisanim dokumentima javljaju se i prvi sačuvani spomenici o samom tom jeziku. Konstantin Filozof (pisac s kraja XIV i početka XV vijeka) u svome spisu Skazanie izjavljena opismeneh, uz bugarski, srpski, slovenski, češki i hrvatski jezik, navodi i bosanski jezik. Jedan od najstarijih spomena bosanskoga jezika nalazi se i u notarskim knjigama grada Kotora. Dana 3. jula 1436. godine 
mletački knez u Kotoru kupio je 15-godišnju djevojku "bosanskog roda i heretičke vjere zvanu bosanskim jezikom Djevenu". Na taj način i samim imenovanjem bosanski govor i pisani jezik već $u$ $\mathrm{XV}$ vijeku prati izgrađena svijest o njegovom postojanju, koja se iskazuje i nazivom toga jezika. Istim onim nazivom koji je danas u zvaničnoj upotrebi (Jahić 2000).

Bosančica iz globalne upotrebe nestaje reformom ćiriličnog pisma Vuka Karadžića, ali se nije prestala koristiti u privatnoj upotrebi. Vukova ćirilica je imala 29 slova, od kojih su 24 bila iz staroslavenske azbuke. Upotreba novog pisma ozvaničena je izdavanjem prvih bosanskohercegovačkih novina Bosanski vjestnik od 7. aprila 1866. godine.

$\mathrm{U}$ vrijeme osmanske vladavine u Bosni nastaje još jedno pismo koje se zove arebica. Arebica je nastala reformom arapskog pisma, jer se nije moglo pisati arapskim pismom na maternjem jeziku. S ovim pismom nastaje i alhamijado književnost i pismenost. Riječ alhamijado potječe od španske modificirane riječi arapskog jezika "al-adžemije" (nearapski, strani) (Huković 1986). Njom su Španci označavali pisanje arapskim pismom na španskom jeziku. S alhamijado književnošću i pismenošću javlja se i jedna od naših prvih književnica - Umihana Čuvidina.

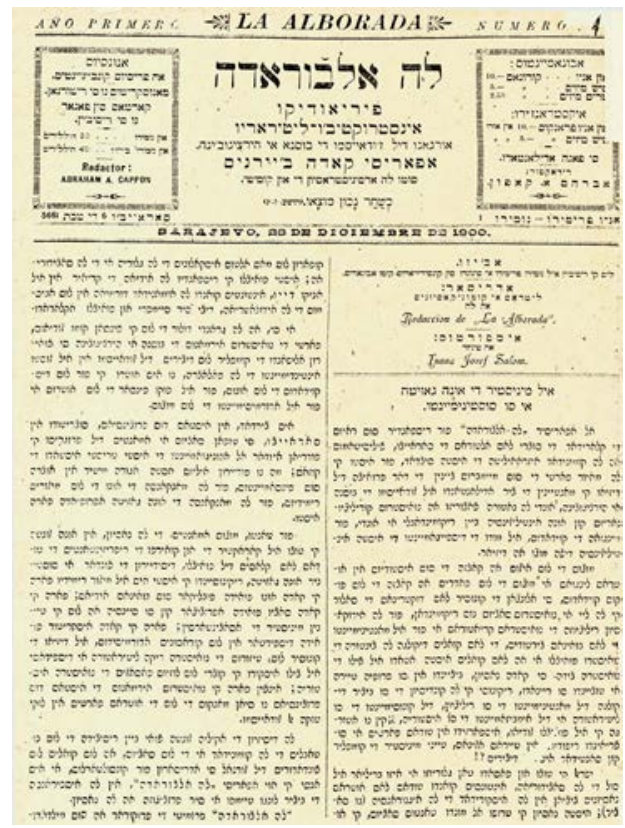

S obzirom na to da smo naveli mnoga pisma koja su korištena u Bosni i Hercegovini, ne možemo da izostavimo ni hebrejsko pismo. Ono se počelo upotrebljavati dolaskom Jevreja protjeranih iz Španije 1492. godine. Dječaci svoje obrazovanje stječu u općim školama, kao i kod privatnih učitelja i porodice. Krajem XVIII stoljeća osnovana je talmudska škola u kojoj su rabini bili bosanskohercegovački Jevreji. Knjige koje su objavljivali bili su prijevo- di sa latinskog i španskog na ladino jezik (jevrejsko-španski), a tek u XIX stoljeću počinju više koristiti latinicu i ćirilicu. Jedan primjer korištenja ladino i hebrejskog jezika je časopis La Alborada (1900-1901), čiji se original čuva u Nacionalnoj i univerzitetskoj biblioteci BiH. Tekstovi su bili na jevrejsko-španskom (ladino) i hebrejskom jeziku na kvadratno-hebrejskom i raši pismu.

\section{Biblioteke u Bosni i Hercegovini}

Za nastanak biblioteka bila su potrebna tri uslova: pojava pisma, književnih spomenika i sloja obrazovanih ljudi koji su znali cijeniti knjigu. Sama riječ je grčko-latinskog porijekla - biblion: knjiga i theke: spremište (Memija 2007).

Otkada je čovjek počeo da prikuplja knjige, rukopise, zapise i bilješke u kojima su zabilježena razna znanja, zapažanja, pouke i misli, od tada datira pojava biblioteka koje su u toku raznih epoha prolazile kroz različite forme, razne organizacije i prilike. Takav je slučaj kod svih naroda i svih zemalja.

I biblioteke nastale na teritoriji Bosne i Hercegovine prošle su kroz slične faze kroz koje su prolazile i u ostalim zemljama. Najprije su se pojavile manastirske biblioteke i biblioteke raznih vjerskih ustanova, a zatim biblioteke kulturno-prosvjetnih društava, zavoda i ustanova. Dijelile su se na dva tipa biblioteka: istočnjačke i zapadne. U manastirima se razvila prepisivačka djelatnost, posebno u XVIII stoljeću, kada postupno dolazi štampana knjiga iz Rusije. Za vrijeme srednjovjekovne samostalnosti najpoznatije biblioteke bile su u katoličkim samostanima u Fojnici, Kreševu, Sutjesci, Visokom itd. U pravoslavnim manastirima bile su u Loznici kod Vlasenice, Papraći kod Tuzle, Ozrenu kod Maglaja i Moštanici kod Bosanske Dubice...

Prva štamparija u Bosni i Hercegovini bila je smještena u pravoslavnoj crkvi Svetog Georgija u Sopotnici blizu Goražda. Osnivač štamparije bio je Božidar Goraždanin iz Mileševa, a štamparija je djelovala od 1529. do 1531. godine. Vodio ju je njegov sin, jeromonah Teodor iz manastira Mileševa, i drugi sin Đurađ Ljubavić. Štamparija je u početku bila smještena u Veneciji, te "(...) odmah nakon dovršenog rada oko 'Služabnika' prenesena je štamparija iz Mletaka u Goražde i smještena u hram svetog velikomučenika Georgija, zadužbinu slavnoga hercega Stjepana" (Kreševljaković 1920). U štampariji su se odštampale tri knjige, već navedeni Služabnik (ili Liturgijar), Psaltir sa posledovanjem i časlovcem i Molitvenik (ili Trebnik).

Od XVI do XIX stoljeća u Bosni i Hercegovini je osnovano preko 100 medresa i svaka je imala svoju manju ili veću biblioteku. Za orijentalne su karakteristične privatne biblioteke, koje su u svojim domovima formirali imućniji i učeni ljudi. 
Prva poznata biblioteka je Gazi Husrev-begova, osnovana od fonda koji je ostao od istoimene medrese, a osnovana je 1537. godine. Gazi Husrev-begova biblioteka posjeduje najviše rukopisa na turskom jeziku, nešto manje na arapskom, a najmanje na perzijskom. Danas je Gazi Husrev-begova biblioteka jedna od najopremljenijih i najmodernijih biblioteka u BiH i šire.

Karađoz-begova biblioteka u Mostaru bila je druga po bogatstvu knjižnog fonda u Bosni i Hercegovini. Nalazila se u posebnoj prostoriji medrese koju je, također, sagradio Karađozbeg.

$\mathrm{U}$ austrougarskom periodu, u kojem je zbog razvijene štampe bilo mnogo jednostavnije doći do knjige, među privatnim bibliotekama ističu se ona Mehmeda Enverije Kadića (1855-1931), koja je veoma bogata rukopisima i dokumentima, te biblioteka Silvija Strahimira Kranjčevića (1865-1908). U Mostaru se nalazi Muzej i biblioteka Alekse Šantića (1868-1924), pjesnika koji je svoj afinitet za poeziju iskazao i u skupljanju knjiga za svoju biblioteku.

U Austro-Ugarskoj monarhiji formiraju se različita društva i uz njih biblioteke. Najprije su to interkonfesionalna udruženja: pjevačka, tamburaška, a zatim i kulturno-prosvjetna. Tu se knjiga čita, o njoj se razgovara, ali i počinje pisati.

Prvi svjetski rat umnogome je zaustavio različite kulturne aktivnosti, pa i bibliotekarstvo. Rat je bio uzrok potpunog ili djelomičnog nestanka brojnih biblioteka, propadanja raznih dokumenata. Biblioteke i bibliotečka aktivnost, razumljivo, dijele sudbinu ukupnih društvenih prilika. Sažeta slika stanja bosanskohercegovačkih biblioteka, odnosno bibliotekarstva u austrougarskom vremenu, može se posmatrati na dva načina: kao privatna inicijativa $\mathrm{i}$ kao potpora države (Hadžiosmanović 1982).

Jedna od važnijih biblioteka iz ovog perioda je i biblioteka Zemaljskog muzeja $\mathrm{BiH}$. Ona se po veličini fondova i značaju nalazila rame uz rame sa Gazi Husrev-begovom bibliotekom. Ona "je smatrana jedinom državnom (centralnom) bibliotekom" (Bašović 1986).

Biblioteke nacionalnih i radničkih društava, kao privatne, nastajale su i materijalno funkcionisale isključivo u zavisnosti od osnivača društva. Nisu bile usklađene pravilima, vođene su bez stručnog kadra $\mathrm{i}$ jedinstvenog sistema. Tu su uspijevale da se održe i biblioteke konfesionalnih zajednica. Ono što su primale od vladajućeg režima nije bilo dovoljno da se održe. Za ove biblioteke se može reći da su, zapravo, vid samostalnog, nezavisnog bibliotekarstva naslijeđenog iz ranijih vremena.

Država se brinula za školske i naučne biblioteke. Postojala su određena pravila u vođenju biblioteka, obradi građe i samom odnosu prema publikacijama.
U skladu s tim ove biblioteke su bile i bolje opremljene i stručnije sređene nego biblioteke vjerskih organizacija i radničkih udruženja.

"Jedna od bitnih značajki biblioteka ovog tla i $\mathrm{u}$ prethodnom i u ovom periodu jeste njihova razjedinjenost i usitnjenost. Nepostojanje ustanova tipa nacionalne biblioteke učinilo je da se bibliotekarstvo kao grana kulturne aktivnosti upravo tako i razvija. To je posljedica političkih i društvenih prilika toga doba." (Hadžiosmanović 1982)

\section{Umjesto zaključaka}

Iz ovog kratkog predstavljanja pisama korištenih u našoj zemlji možemo vidjeti da je Bosna i Hercegovina prostor višejezičnosti i polialfabetizma. $\mathrm{Na}$ ovako malom prostoru upotrebljavalo se grčko, etrursko i rimsko pismo, tj. latinica, kao i rune, te glagoljica, ćirilica, arapski jezik i pismo, a poslije su i ta pisma reformisana i nastaju bosančica, arebica, ladino i alhamijado književnost i pismenost, kao i bosanski jezik. Takav susret raznih jezika i pisama teško je naći bilo gdje u svijetu. Neraskidiva veza pisma, knjige i biblioteke prožimala se stoljećima. Bosanskohercegovačko bibliotekarstvo ima veoma dugu i bogatu tradiciju. Stoljećima je istrajavalo noseći obilježja bremenite prošlosti ovog tla. Naravno, moderno bibliotekarstvo kao sistem razvija se tek $\mathrm{u}$ godinama poslije Drugog svjetskog rata. U tom vremenu su se stekli uslovi i za nastanak i razvoj centralne nacionalne biblioteke. Ovakva institucija bila je potrebna svim narodima koji su živjeli u Bosni i Hercegovini jer je trebala da ujedini sve male biblioteke i vrši funkciju nacionalne, centralne, naučne $i$ razvojne biblioteke.

U skladu s tim je 22. maja 1945. godine osnovana Narodna biblioteka Federalne Bosne i Hercegovine, koja Uredbom Ministarstva prosvjete dobiva zadatak da vrši funkciju nacionalne, centralne naučne i razvojne biblioteke u Bosni i Hercegovini.

Sama odluka je objavljena u Službenom listu Federalne Bosne i Hercegovine 31. 10. 1945. godine. 


\title{
Literatura
}

- “Arheološka istraživanja u Rapovinama kod Livna”. https://arheohercegovina.com/2013/07/24/arheoloska-istrazivanja-u-rapovinama-kod-livna/. Datum pristupa: 5. 4. 2017.

- Bašović, Ljubinka. 1986. Biblioteke i bibliotekarstvo u Bosni i Hercegovini: 1918-1945. Sarajevo: "Veselin Masleša".

- Bogićević, Vojislav. 1975. Pismenost u Bosni i Hercegovini: od pojave slovenske pismenosti $u I X$ v. do kraja austrougarske vladavine u Bosni i Hercegovini 1918. godine. Sarajevo: "Veselin Masleša".

- Bojanovski, Ivo. 1988. Bosna i Hercegovina u antičko doba. Sarajevo: Akademija nauka i umjetnosti Bosne i Hercegovine.

- Gavran, Ignacije. 1988. "Fra Matija Divković (1564.-1631.)" U Putovi i putokazi: 14-17. Sarajevo: Svjetlo riječi. Dostupno i na: https:/www.bosnasrebrena.ba/node/250.

- Huković, Muhamed. 1986. Alhamijado književnost $i$ njeni stvaraoci. Sarajevo: Svjetlost.

- Isaković, Alija, i Popadić, Milosav, ur. 1982. Pisana riječ u Bosni i Hercegovini od najstarijih vremena do 1918. godine. Sarajevo: "Veselin Masleša".

- Jahić, Dževad, Halilović, Senahid, i Palić, Ismail. 2000. Gramatika bosanskoga jezika. Zenica: Dom štampe.
- Kreševljaković, Hamdija. 1920. "Štamparije u Bosni za turskog vremena: 1529-1878" Građa za povijest književnosti Hrvatske: 1-41.

- Markešić, Luka Mirko. 1979. "Katolička reforma i njezin značaj 'za narod puka slovinskoga' prema djelima fra Matije Divkovića (1563-1631)" U Povijesno-teološki simpozij u povodu 500. obljetnice smrti bosanske kraljice Katarine, uredio Marko Karamatić et al., 151-163. Sarajevo: Franjevačka teologija u Sarajevu - Kršćanska sadašnjost.

- Memija, Emina. 2007. Od slike do knjige: iz historije pisma, knjige, štampe i biblioteke. Sarajevo: Nacionalna i univerzitetska biblioteka Bosne i Hercegovine.

- Pejanović, Đorđe. 1960. Istorija biblioteka u Bosni i Hercegovini: od početka do danas. Sarajevo: "Veselin Masleša".

- Vego, Marko. 1970. Zbornik srednjovjekovnih natpisa Bosne i Hercegovine. Knj. 4. Sarajevo: Zemaljski muzej.

\section{Napomena:}

Slike runa i novca Stjepana Tomaša su preuzete iz Isaković i Popadić 1982.

Slike Povelje Kulina bana, Nauka krstjanskog za narod slovinski i La Alborade u radu su dio kolekcija Nacionalne i univerzitetske biblioteke Bosne i Hercegovine.

\section{THE WRITTEN WORD AND LIBRARIES IN BOSNIA AND HERZEGOVINA UNTIL THE 20TH CENTURY}

\begin{abstract}
The cultural heritage of Bosnia and Herzegovina in all its aspects and in any time or period testifies to the complexity of life on this ground. The paper presents the flow of the written word and creation of the libraries in Bosnia and Herzegovina.

We will see that exactly in the domain of writing systems and books, better than in any other medium, the presence of certain influential sphere, as well as the original creative spirit of the people of this country is recognized. In our country, four writing systems were used in the Middle Ages. These were Greek and Latin writing systems, as well as Glagolitic and Cyrillic script. The reason for this curiosity is encounter of different civilizations that have also evolved here. Also, this kind of example of use of different writing systems in a small region is unique.

Through the writing systems and books, we come to occurrence of the first libraries in the Bosnia and Herzegovina.

As well as the books are one of the essential elements for spreading literacy, libraries are one of the most important means to facilitate that expansion and that book can reach their readers.

Libraries and library science in Bosnia and Herzegovina have passed through various phases but they have stayed true to their function throughout the centuries, to the development of culture, to the mass education and to the science. Libraries were and still are the pillar of civilization.
\end{abstract}

Keywords: literacy, written word, libraries, culture, education, Bosnia and Herzegovina 